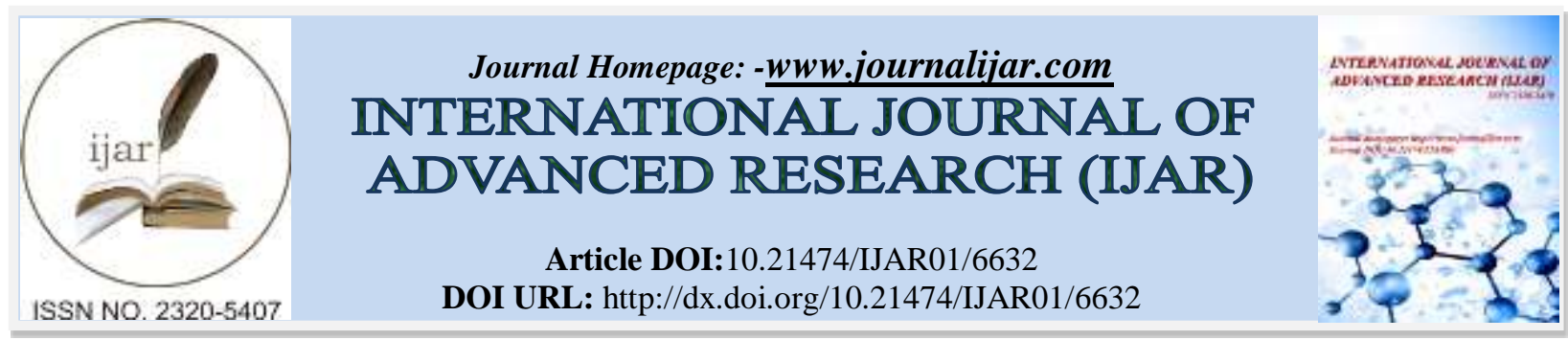

RESEARCH ARTICLE

\title{
HISTOPATHOLOGICAL EVALUATION OF CHRONIC NON HEALING ULCERS OF SKIN IN PATIENTS REFERRED TO TERTIARY CARE HOSPITAL IN KASHMIR.
}

Baba iqbal khaliq ${ }^{1}$, lateef ahmad wani ${ }^{2}$, suhail farooq ${ }^{1}, \operatorname{Jibran}_{\text {Amin }}{ }^{1}$, Syed Imtiyaz ${ }^{1}$ and Hilal Ahmad ${ }^{3}$.

1. Senior Resident, Department of Pathology, GMC Srinagar 190010.

2. Associate Professor, Department of Pathology, GMC Srinagar 190010.

3. Senior Resident, Department of Surgery, GMC Srinagar 190010.

\section{Manuscript Info}

Manuscript History

Received: 24 December 2017

Final Accepted: 26 January 2018

Published: February 2018

Keywords:-

Non-healing ulcer, malignant, benign, squamous cell carcinoma, neuropathic diabetic ulcer, tuberculosis.

\section{Abstract}

Background: Skin is the single largest organ of the body that protects against mechanical trauma, radiation and infection. Because of its complexity a wide range of diseases can develop from the skin ranging from infectious diseases to malignancy, some of which may present as non-healing ulcers. Non healing ulcers are an important cause of morbidity in developing countries. Study of non-healing skin ulcers is challenging and at times even frustrating than any other skin lesions. This study was taken keeping in view the present scenario were patient with non-healing ulcers go unnoticed for a long time without biopsy resulting in uncertainty of developing malignancy which can otherwise be identified at a very early stage by early histopathological examination.

Aim: Aim of this study was to study the histopathological outcome of non-healing ulcers in this geographical area where much is not known about the etiology of non-healing ulcers.

Methodology: This study was hospital based two years prospective study extending from January 2016 to December 2017 conducted in Department of Pathology, Government Medical College Srinagar. During this period patients referred from peripheral hospitals with ulcers that had not healed for 4 weeks or more after conventional therapies were included in this study. The detailed history and clinical examination findings were retrieved from the case files. Biopsies received were processed as per the standard protocol and slides were examined by the senior pathologist in the Department of Pathology, Government Medical College Srinagar.

Results: During the two years period department received biopsies from 282 patients with non-healing ulcers. Out of 282 patients 180 were males and 102 were females with a M:F ratio of 1.76:1. Out of the 282 cases $100(35.46 \%)$ were diagnosed as malignant ulcers and $182(64.54 \%)$ were diagnosed as benign ulcers (Table 1). Out of the 282 cases, 70 cases $(24.82 \%)$ were found to be neuropathic diabetic ulcers, $52(18.43 \%)$ were diagnosed as tubercular ulcers, $44(15.60 \%)$ as infectious, $4(1.42 \%)$ as leprosy, $4(1.42 \%)$ cases were due to parasitic infection (cutaneous leishmaniasis) and 8 cases $(2.83 \%)$ as others. Benign ulcers were found to be fairly common below 50 years 
of age. Lupus Vulgaris was found to be the commonest form among the tubercular ulcers constituting $75 \%$ of the tubercular ulcers followed by Scrofuloderma accounting for $25 \%$ of the cases. Among malignant cases, that Squamous cell carcinoma is the most common variety of malignancy encountered in an ulcer accounting for $82 \%$ of cases followed by Basal cell carcinoma 14\% and malignant melanoma $4 \%$.

Conclusion: Non-healing ulcers can be encountered at any age and etiology may vary from one geographical region to other and may also be different in different racial groups. Thus beside a good clinical diagnosis, early biopsy to rule out malignancy and identify the etiology is mandatory for a better outcome and minimize the morbidity and mortality among patients with non-healing ulcers.

Copy Right, IJAR, 2018,. All rights reserved.

\section{Introduction:-}

Skin is the single largest organ of the body that protects against mechanical trauma, radiation and infection. Because of its complexity a wide range of diseases can develop from the skin ranging from infectious diseases to malignancy, some of which may present as non-healing ulcers ${ }^{1}$.

General surgical referral guidelines defines any non-healing ulcer as that which has been present for 3-4 weeks duration and has not responded to conventional therapies ${ }^{1}$. Sometimes a need of surgical intervention is forced upon. Although histopathology remains the gold standard for most dermatologic diagnoses, it must be recognized that not all lesions are amenable to definitive "specific" histologic diagnosis 2 .

Chronic wounds are characterized clinically as wounds that have failed to proceed through a biologically predictable and timely healing process and either are unresponsive to initial therapy or persist following appropriate wound care $^{2-3}$ They are often identified by the presence of a raised, hyperproliferative, yet nonadvancing wound margin ${ }^{2,3}$. Understanding the pathological alterations of wound tissue that are refractory to standard wound therapy is essential for effective wound management and healing. The presence of a chronic wound can result in significant morbidity or mortality.

Chronic cutaneous ulcers are common in the developing countries like India, especially in rural areas with poor living conditions. These ulcers often result from trauma, vascular insufficiency, neuropathy, leprosy, diabetes, malignancy or hemoglobinopathies ${ }^{1}$. If poorly managed these lesions may undergo malignant transformation ${ }^{4-6}$.

Thus, the study of non-healing skin ulcers is challenging and at times even frustrating than any other skin lesions. This study was taken keeping in view the present scenario were patient with non-healing ulcers go unnoticed for a long time without biopsy resulting in uncertainty of developing malignancy which can be identified at a very early stage by early histopathological examination.

\section{Material And Methods:-}

This study was hospital based two years prospective study extending from January 2016 to December 2017 conducted in Department of Pathology, Government Medical College Srinagar. During this period patients referred from peripheral hospitals with ulcers that had not healed for 4 weeks or more after conventional therapies were included in this study. The detailed history and clinical examination findings were retrieved from the case files. Biopsies received were processed as per the standard protocol and slides were examined by the senior pathologist in the department.

\section{Results:-}

During the two years period department received biopsies from 282 patients with non-healing ulcers. Out of 282 patients 180 were males and 102 were females with a M:F ratio of 1.76:1. Out of the 282 cases 100 (35.46\%) were diagnosed as malignant ulcers and $182(64.53 \%)$ were diagnosed as benign ulcers (Table 1 ). 
Table 1:- Etiological types of Non-healing ulcers.

\begin{tabular}{|c|c|c|}
\hline Etiological type & Number of patients & Percentage \\
\hline Malignant ulcers & 100 & $35.46 \%$ \\
\hline Neuropathic diabetic ulcers & 70 & $24.82 \%$ \\
\hline Tubercular ulcers & 52 & $18.44 \%$ \\
\hline Infectious ulcers & 44 & $15.60 \%$ \\
\hline Leprosy & 4 & $1.42 \%$ \\
\hline Cutaneous leishmaniasis & 4 & $1.42 \%$ \\
\hline Others & 8 & $2.84 \%$ \\
\hline Total & 282 & $100 \%$ \\
\hline
\end{tabular}

Out of the 282 cases, 70 cases $(24.82 \%)$ were found to be neuropathic diabetic ulcers, $52(18.43 \%)$ were diagnosed as tubercular ulcers, $44(15.60 \%)$ as infectious, $4(1.42 \%)$ as leprosy, $4(1.42 \%)$ cases were due to parasitic infection (cutaneous leishmaniasis) and 8 cases $(2.83 \%)$ as others. Benign ulcers were found to be fairly common below 50 years of age. Lupus Vulgaris was found to be the commonest form among the tubercular ulcers constituting $75 \%$ of the tubercular ulcers followed by Scrofuloderma accounting for $25 \%$ of the cases. Among malignant cases, that Squamous cell carcinoma is the most common variety of malignancy encountered in non-healing ulcer accounting for $82 \%$ of cases followed by Basal cell carcinoma $14 \%$ and malignant melanoma $4 \%$.

Swabs from wound of 44 patients diagnosed as infectious ulcers were sent for culture and sensitivity tests, Staphylococcus was found to be the most common pathogen accounting for $50 \%$ of the bacteriological isolates. This was followed by klebsiella (16.67\%), Proteus (16.67\%) and Pseudomonas and Streptococcus was seen in $8.33 \%$ each. The group of “other ulcers' consist of venous ulcers which were diagnosed clinically and radiologically but no histopathological evidence could be found, ulcers due to foreign body granuloma histopathologically and ulcers for which no etiology could be identified histologically. Hence these ulcers could not be typified in definite etiological classes and were grouped together as others.

\section{Discussion:-}

Non healing ulcers are an important cause of morbidity in developing countries ${ }^{7,8}$. This may be explained by the poor socioeconomic conditions, poor health services in remote areas and lack of public awareness. In contrast with the developed countries, little is known about the prevalence and etiology of non-healing ulcers in these areas. One study from Nigeria reported that the most common etiologic factors were trauma, diabetes mellitus and sickle cell disease $^{9}$ Depending on the region, infectious causes such as cutaneous Leishmaniasis or Buruli ulcer may be encountered $^{10,11}$.

In contrast venous ulcers are most common cause of ulcers in developed countries but are reported to be uncommon in tropical countries ${ }^{12}$, Zeegelar et $\mathrm{al}^{13}$ also reported that venous ulcers and diabetic ulcers are common in developed countries. In his study we found that the most common cause of non- healing ulcers in this region are malignant ulcers found in 100 patients $(35.46 \%)$ followed by neuropathic diabetic ulcers 70 patients $(24.82 \%)$, Tuberculosis in 52 patients (18.43\%), Infectious causes were found in 44 patients $(15.60 \%)$, Leprosy in 4 patients (1.42\%), Cutaneous Leishmaniasis in 4 patients $(1.42 \%)$ and other causes in 8 patients $(2.84 \%)$. Results of our study were different from western studies were venous ulcers were found as most common cause by Mekkes et al ${ }^{14}$. Zeeglar et $\mathrm{al}^{13}$ in his study found infectious causes followed by malignancy as the most common cause of non-healing ulcers. Results of our study were similar to studies from India by Sarkar PK ${ }^{12}$ and Saraf $\mathrm{SK}^{32}$. The differences from western studies may be due to different geographical location, tropical climate, poor health services, different racial group and illetracy, ignorance.

In the present study, malignant ulcers were found to be the most common cause of non-healing ulcers of skin accounting for $35.46 \%$. Of these squamous cell carcinoma is the most common $82 \%$ cases followed by Basal cell carcinoma (14\%) and Malignant melanomas (4\%). This finding is in concordance with that reported by Yakubu et $\mathrm{al}^{15}$. No venous or arterial ulcers were found histologically. However, two cases of venous ulcers were found which were diagnosed clinically and radiologically but no specific histologic features were identified to typify them, hence these were grouped under "other ulcers". Among the malignant ulcers Squamous cell carcinoma is the most common. Patients with non-healing ulcers for more than two years usually had malignant ulcers. Similar conclusions were drawn by Singh et $\mathrm{al}^{16}$, Talvalkar et $\mathrm{al}^{17}$, Schreiber et $\mathrm{al}^{18}$ and Adinarayan $\mathrm{M}$ et $\mathrm{al}^{19}$. In the present study 11 
patients presented with Marjolin's ulcer, and were confirmed histopathologically as Squamous cell carcinoma. This is in concordance with the conclusion drawn by Morra and colleagues ${ }^{20}$ and Jellouli \& colleagues ${ }^{21}$.

It was observed that common age group for malignant ulcer was 60-70 years followed by 50-60 years with a male preponderance. Similar conclusions were drawn by Singh et $\mathrm{al}^{16}$. Also malignancy below the age of 40 years was rare, only 4 cases were detected. This matches with that reported by Singh et $\mathrm{al}^{16}$ who found 4 cases below the age of 30 years.

We observed neuropathic diabetic ulcers as the second common cause for non-healing ulcers, accounting for $24.82 \%$ of the non-healing ulcers. This is in accordance with studies by Neil et $\mathrm{al}^{33}$ who found that approximately $20 \%$ of all non-healing ulcer related admissions in UK were due to diabetic foot ulcer disease. Alex and colleagues also reported an incidence rate that ranged from $8 \%-17 \%$. The above studies are in contrast to the figures reported by Ch. Manes et $\mathrm{al}^{34}$ and Nyamu et $\mathrm{al}^{35}$ being $4.75 \%$ and $4.6 \%$ respectively.

The present study also observed two age peaks in presentation of the patients with non-healing ulcers due to diabetes. The first peak is in the $6^{\text {th }}$ decade accounting for $38.5 \%$ of the patients and the 2 nd peak is in the $5^{\text {th }}$ decade accounting for $30.8 \%$ of the patients. The studies by Bansal et $\mathrm{al}^{36}$ and Neil et $\mathrm{al}^{33}$ reported similar age incidences. Diabetic ulcers were relatively common in males accounting for $61.5 \%$ and less common in females accounting for $38.5 \%$. This is similar to Gaur et $\mathrm{al}^{37}$ who reported a male to female ratio of 1.2:1. However $\mathrm{Ch}$. Manes et $\mathrm{al}^{34} \mathrm{did}$ not establish different rates between male and female population.

This was followed by tubercular ulcers $18.44 \%$. Although this is in contrast to the conclusion drawn by M. Naveduz Zafar et $\mathrm{al}^{22}$, Binod Kumar Thakur and colleagues ${ }^{23}$ and Padmavathy and colleagues ${ }^{24}$ who reported incidence of cutaneous Tuberculosis of $3.62 \%, 0.25 \%$ and $1.6 \%$ of all skin biopsies respectively but in their studies they have taken all skin biopsies and in the present study we have included cases which have presented with non-healing ulcers only.

In the recent years, with the emergence of anti-Tubercular drug resistant strains and AIDS epidemic, there is a worldwide rise in the incidence of Tuberculosis. More so in the poverty struck areas of the world due to poor nutrition, poverty, non-availability of diagnostic aids and treatment, over-crowding, ignorance about the disease, rise in immunosuppressive therapy, decline in Tuberculosis control efforts and emergence of resistant strains of Mycobacterium tuberculosis have amplified the situation ${ }^{25,26}$.

Among the Tubercular ulcers most patients presented at the 2nd \& 3rd decades which was in accordance with Binod Kumar Thakur and his colleagues ${ }^{23}$. Padmavathy and colleagues also reported a similar observation ${ }^{24}$. Lupus Vulgaris was found to be the most common form followed by Scrofuloderma. Similar to this study, M. Naved uz Zafar et $\mathrm{al}^{22}$ also reported Lupus Vulgaris as the most common form. Similar results were seen by Satyanarayan ${ }^{22}$, Singh et $\mathrm{al}^{28}$ and Kumar et $\mathrm{al}^{29}$ our study we could demonstrate Acid Fast Bacilli (AFB) in $19 \%$ of patients by Ziehl Neelsen staining (ZN stain) method in pathological sections, this is similar to studies by M. Naveduz Zafar et al ${ }^{22}$ who found AFB in $18.42 \%$ cases and Ranjan Agarwal et al ${ }^{31}$ who found AFB in $17.19 \%$ cases but is not in accordance with the results of Mahaisavariya et $\mathrm{al}^{30}$ who found AFB in $30.77 \%$ cases.

In the present study non-healing ulcers due to infectious etiology accounts for $15.60 \%$. Bacteria are the main cause among the infectious ulcers in our setting; culture and sensitivity were performed Staphylococcus being found as the most common causative agent accounting for $50 \%$ of the infectious causes followed by Klebsiella $16.67 \%$, Proteus accounting for $16.67 \%$, Pseudomonas and Streptococcus accounting for $8.33 \%$ each. These results are in accordance with the results reported by J. E. Zeegalaar et $\mathrm{al}^{38}$.

In similar studies by Tan et $\mathrm{al}^{39}$, Erikson et $\mathrm{al}^{40}$ and Giacometti et $\mathrm{al}^{41}$ reported Staphylococcus as the most common organism.

However other studies by Gaur et $\mathrm{al}^{37}$ reported Enterococcus as the most common organism and the study by Bansal et $\mathrm{al}^{36}$ reported pseudomonas as the most common organism.

The reason for such discrepancy could not be assessed but may be due to the environmental factors and the intrinsic properties of the microorganism themselves as reported by Diana et $\mathrm{al}^{42}$ and Mrek et $\mathrm{al}^{43}$. 


\section{Summary and Conclusion:-}

The most common cause of non-healing ulcers in this geographical area was found to be malignancy (35.46\%). The other causes identified were Neuropathic Diabetic ulcers (24.82\%), Tubercular ulcers (18.44\%), and Infectious Ulcers (15.60\%), Leprosy (1.42\%), Cutaneous Leishmaniasis (1.42\%) and other ulcers (2.84\%). Among the malignant ulcers, Squamous cell carcinoma is the most common form (82\%); followed by Basal cell carcinoma (14\%) and Malignant Melanoma (4\%). Lupus vulgaris was found to be the most common form (75\%) followed by Scrofuloderma (25\%) among tubercular ulcers. Diabetic ulcers were found to be more common in the age group of 50-60 years. Males are commonly affected. Staphylococcus was the most common organism isolated (50\%) followed by Klebsiella (16.67\%), Proteus (16.67\%), Pseudomonas (8.33\%) and Streptococcus (8.33\%).

Thus it can be concluded from the study that non-healing of ulcers can be encountered at any age and etiology may vary from patient to patient, one geographical region to other and may also be different in different racial groups. Thus beside a good clinical diagnosis, early biopsy to rule out malignancy and identify the etiology is mandatory for a better outcome and minimize the morbidity and mortality among patients with non-healing ulcers.

\section{References:-}

1. General Surgery Referral Guidelines, Madigan Army Medical Centre, Tacoma, Washington-98431

2. Mustoe TA, O-Shaughnessy K, Kloeters O. Chronic wound pathogenesis and current treatment strategies: a unifying hypothesis. Plast Reconstr Surg 2006; 117(7 Suppl): 35S-41S.

3. Werdin F, Tennenhaus M, Schaller HE, Rennekampff HO. Evidence-based management strategies for treatment of chronic wounds. Eplasty 2009; 9: e19.

4. Asuquo M, Ugare G, Ebughe G, Jibril P. Marjolin's ulcer: The importance of surgical management of chronic cutaneous ulcers. Int J Dermatol 2007; 46: 29-32.

5. Chong AJ, Kalein MB. Images in clinical medicine. Marjolin’s ulcer. N Engl J Med. 2005; 352 : e9.

6. Smith J, Mello LF, Nogueira Nato NC, Meohas W, Pinto LW, Campos VA, Barcellos MG, Fiod NJ, Rezende JF, Cabrel CE. Malignancy in chronic ulcer and scars of the leg (Marjolin's ulcer): a study of 21 patients. Rehabil 2001; 65: 69.

7. Sturm AW, Jamil B, Mc Adam KPWJ, Khan KZ, Parveen S, Chian T, Hussain R. Microbial Colonizers in leprosy skin ulcers and intensity of inflammation. Int J Lepr 1996; 64: 274-281.

8. Robinson DC, Hay RJ. Tropical Ulcer in Zambia. Trans R Soc trop med Hyg 1986; 80: 1432-137.

9. Ohanka EC, O’Sarenkhoc O. In-patient management of leg ulcers. East Afr. Med J 1999; 76: 687-689.

10. Herwaldt Bl. Leishmaniasis. Lancet 1999; 354: 1191-1199.

11. Van der Werf TS, van der Grwaf WT, Tappeco JW, Asiedu K. Mycobacterium ulcerans infections. Lancet 1999; 354: 1013-8.

12. Sarkar PK, Ballantyre S. Management of leg Ulcers. Post Grad Med J 2000; 76: 674-682.

13. Zeegelar JE, Stroink AC, Steketee QH, Faber WR, Vanderwal AC, Komolafe IOO, Dzamalale C, Chibwana C, Wedle HF, Ed Zijlstan. Etiology and incidence of chronic ulcers in Blatyre, Malawi. Int. Journal of Dermatology 2006 Aug; 45(8): 933-6.

14. Mekkes JR, MCoots MA, AC Van Der Wal and JD Bos. Causes, investigation and treatment of leg ulceration. British Journal of Dermatology 2003; 148: 388-401.

15. Yakubu A, Mabogunje OA. Squamous Cell Carcinoma of the skin in Africans. Trop Geogr Med 1995: 2; $91-93$.

16. Laishram RS, Banerjee S, Punyabati P, Durlar L, Sharma C. Pattern of skin malignancies in Manipur in India: A 5 years histopathological review. Journal of Pakistan Association of Dermatology, 2010; 20: 128-132.

17. Pandu S. Non-melanoma skin cancer in India: Current scenario. Indian Journal Dermatol 2010; 55: 373-8.

18. Schreiber MM, Shapiro SI, Berry CZ, Dahler RF, Friedman RP. The incidence of skin cancer in Southern Arizona .Arch Dermatol. 1971; 104: 124-7.

19. Adinarayam M, Krishnamurathy SP. Clinicopathological evaluation of non-melanoma skin cancer. Indian J Dermatol 2011; 56: 670-2.

20. Mora RG, Perniciaro C, Cancer of skin in Blacks I. A review of 163 black patients with cutaneous SCC. J Am Acad Dermatol 1981; 5: 535-43.

21. Sabin SR, Goldstein G, Rosenthal HG, Haynes KK. Aggressive squamous cell carcinoma originating as a Marjolin's ulcer. Dermatol Surg. 2004; 30: 229-230.

22. Naved uz Zafar M, Memon MA, Asha MA, Shaheen, Agha A, Hashim Y, Mirza T, Muhammad D, Rizvi S. Pattern of cutaneous tuberculosis as identified by morphological study of skin lesions at Jinnah Postgraduate Medical Center, Karachi. Gomal Journal of Medical Sciences January-June 2010; Vol. 8, No.1 
23. Binod Kumar Thakur, Shikha Verma, Debeeka Hazarika. A clinicopathologic study of cutaneous tuberculosis at Dibrugarh District, Assam. Indian J Dermatol 2012; 57: 63-5.

24. Padmavathy L, Rao LL, Pari T, Ethirajan N and Swamy BK. Lupus vulgaris and tuberculosis verrucosa cutis A clinical, pathological, epidemiological study of 71 cases. Indian J Tuberc 2008; 55: 203-209.

25. Kumar B, Muralidhar S. Cutaneous tuberculosis: a twenty year prospective study. The International Journal of Tuberculosis and lung disease 1995; 3: 494-500.

26. Sehgal VN, Srivastava G, Khurana VK. An appraisal of epidemiological, clinical, bacteriologic, histopathologic and immunologic parameters in cutaneous tuberculosis. Int J Dermatol 1987; 26: 521-6.

27. Satyanarayan BV. Tuberculoderma - a brief review together with statistical analysis and observation. Ind J Dermatol Venerol 1963; 29: 25-42.

28. Singh G. Lupus vulgaris in India. Ind J Dermatol Venerol 1974; 40: 257-60 .

29. Kumar B, Muralidhar S. Cutaneous tuberculosis: a twenty year prospective study. The International Journal of Tuberculosis and Lung Disease 1995; 3: 494-500.

30. Mahaisavariya P, Manonukul J, Khemngun S, Cshai prasert A. Mycobacterial skin infections. Comparison between histological features and detection of Acid Fast Bacilli in pathologic sections. J Med Assoc Thai 2004; 87: 709-12.

31. Agrawal R, Kumar M, Kumar P. Cutaneous tuberculosis a clinicopathological studyhttp://dx.doi.org/10.7713/ijms.2012.0044

32. Saraf SK, Shukla VK, Kaur P, Pandey SS. A clinico-epidemilogical profile of non healing wounds in an Indian hospitals.

33. Neil HAW, Thompson AV, Thorgood M et al. Diabetes in the elderly, the oxford university diabetes study. Diabetic Med 1989, 6: 608-613.

34. Ch Manes, Papazoglou N, Sorsidou E, Soulis K, Milarkis D, Satsoglou A, Sakallerou A. Prevalence of diabetic neuropathy and foot ulceration: Identification of potential risk factors: http://woundsresearch.com/article/141?p=0,2

35. Nyamu PN, Otieno CF, Amayo EO, McLigyeo SO. Risk factors and prevalence of diabetic foot ulcers at Kenyatta. National Hospital, Nairobi-East African Medical Journal 2003 Jan; Vol. 80, No. 1: pp 36-43.

36. Bansal E, Garg A, Bhatia S, Attri AK, Chader J. Spectrum of microbial flora in diabetic foot ulcers. Indian J Pathol Microbiol 2008; 51: 204-208.

37. Gaur DS, Verma A, Gupta P. Diabetic foot in Uttaranchal. 2007; Vol.9. No.1: P.18-20.

38. Zeegelar JE, Stroink AC, Steketee WH, Faber WR, Vanderwal AC, Komolafe IOO, Dzamalale C, Chibwana C, Wedle HF, Ed Zijlstan. Etiology and incidence of chronic ulcers in Blatyre, Malawi. Int. Journal of Dermatology 2006 Aug; 45(8): 933-6.

39. Tan HH, Tay YK, Goh CL. Bacterial skin infections at a tertiary dermatological centre. Singapore Med J, 1998 Aug; 39(8): 353-6.

40. Erikson G, Eklund $\mathrm{AE}$ and Leallings LO. Clinical significance of bacterial growth in venous leg ulcers. Scandinavian Journal of Infections disease: 1984; Vol. 16, No.2: pages 175-180.

41. Giacometti A, Cirioni O, Schimizzi AM, Prete MSD, Barchiesi F, Errico MMD, Petrelli E and Scalie G. Epidemiology and microbiology of surgical wound infections. J Clin Microbiol. February 2000; Vol. 38, No.2: 918-9222.

42. Paltrey DC, Rhodes B, Chatwood JG. Investigation into microbial flora of healing \& on healing decubitus ulcers. J Clin Pathol 1981; 34: 701-705.

43. Kucharzewski M, Kuyra JM, Basczak E, Franek A. Analysis of the flora of venous and diabetic ulcerations. 